\title{
A Comparative SEM-EDS Elemental Composition of Mud in Coastal Aquaculture Ponds
}

\author{
JATINDRA N. BHAKTA*; Y. MUNEKAGE
}

\begin{abstract}
The present study was aimed to understand the comparative abundance and source of elemental constituents in mud of four coastal shrimp farming areas, Vunh Tau (VT), Nha Trang (NT), Da Nang (DN) and Hue (HU) in Viet Nam using SEM-EDS analysis. Mud samples were collected from shrimp farming coastal zones and used for SEM-EDS analysis. Obtained results clearly revealed that all muds were predominately constituted with $\mathrm{Si}$ (23.39 - 47.42\%), $\mathrm{Al}(4.5-15.9 \%), \mathrm{Fe}(0.59-8.29 \%)$ and $\mathrm{C}$ (6.56 to 12.55\%). Despite that $\mathrm{K}(3.67 \%), \mathrm{Al}(15.9 \%)$, $\mathrm{Fe}(8.29 \%)$ and $\mathrm{Ti}(0.65 \%)$ were distributed at highest percentage in the VT than that of the remaining three stations; $\mathrm{Na}(3.68 \%)$ was prevalent in NT; whereas $\mathrm{Mg}(1.46 \%)$ and $\mathrm{Si}(47.42)$ were abundant with elevated percentage in DN as well as C $(12.55 \%), \mathrm{P}(3.34 \%)$ and S $(2.72 \%)$ pronounced with maximum percentage in HU. Therefore, it may also be concluded that mud of all shrimp ponds are principally composed with $\mathrm{Si}, \mathrm{Al}, \mathrm{Fe}$ and $\mathrm{C}$ as major elemental constituents, whereas remaining other elements are present in low percentage in the mud of shrimp ponds in geochemical profile of Viet Nam. Though it is not possible to ascertain the source of all elements from this study but abundance of $\mathrm{Al}$ and $\mathrm{Fe}$ in the mud of shrimp ponds are largely influenced by the anthropogenic sources. Moreover, from this study it can be suggested that monitoring of elemental composition and their source using SEM-EDS would be a potential tool for understanding the concentration level towards conserving the coastal environment. @ JASEM
\end{abstract}

Soils are mixture of materials derived from substrate weathering and decomposition of organic matters serving several vital functions, but it has significant effect on food production in terrestrial and aquatic compartment in different ways. It is thus of extreme importance to protect this resource and to ensure its sustainability (Wong et al., 2002). Various metallic and nonmetallic elements are responsible for the physico-chemical properties of the soil regulating the numerous chemical and biochemical metabolic pathways which determines the quality of soil. A deficit or excess of these elements can cause serious problems in plant growth and animal and/or human health (Ferguson 1990; Tiller 1989). The total content of trace elements in soils depends mainly upon the bedrock type from which the soil parent material was derived but also on which pedogenic processes were carried out (Mitchell, 1974). Due to natural process, soils of the higher land is transported to the lower land, deposited as sediment at bottom which largely influencing the constituting properties of the mud. Characteristic of the bottom mud is a key factor influencing the physico-chemical properties of the overlaying water as well as productivity in aquaculture system. Therefore, characterization of bottom mud is an important concern in determining the pond quality. The mud involve inputs and losses of substances, movement of substances within pond water and mud, transfer of substances across the soilwater interface, and uptake or release of substances by the soil through ion exchange, dissolution and decomposition (Tchobanoglous and Schroeder, 1987; Bhakta et al., 2007).

Soil micro-morphology is becoming more and more involved in studies on soils as porous media in relation to their physical properties (Chen, 1998). Scanning Electron Microscopy-Energy Dispersive X- ray Spectrometry (SEM-EDS) is a simple, rapid, nondestructive option for soil surface morphology and elemental analysis. It has been greatly used to observe natural soil aggregates (Remley and Bradford, 1989; Sullivan, 1990; Robertson and Eggleton ,1991; Watanabe et al., 1992; Boer and Crosby, 1995; Jeong, 1998; Harris and Hollien, 2000; Laird, 2001), also applied to inorganic soil components and their associations and has the potential to improve the integrity of the data (Reed, 1996). This technique has also been used to observe the microstructure of organic soil components and their associations with inorganic material (Tan, 1985; Chen and Schnitzer, 1976).

Therefore, on account of the above impacts of mud in aquatic ecosystem, the present study includes SEMEDS characterization of mud of the coastal shrimp farming area in Viet Nam, a South East Asian country generally richen with mountains and rapidly developed industries which may largely be responsible for constituting the elemental composition of bottom mud in aquatic environment. As there is no such information so far, therefore, the objective of the present study has been aimed to understand the comparative abundance and source of elemental constituents in mud of different coastal shrimp farming area using SEM-EDS analysis.

\section{MATERIALS AND METHODS}

Study area and sampling: Present investigation considered four coastal shrimp farming zones; Vunh Tau, Nha Trang, Da Nang and Hue located in Viet Nam. Vunh Tau (VT) $\left(10^{\circ} 21^{\prime} 0^{\prime \prime} \mathrm{N}\right.$ and $\left.107^{\circ} 4^{\prime} 0^{\prime \prime} \mathrm{E}\right)$ and Nha Trang (NT) (12 $12^{\circ} 13^{\prime} 40^{\prime \prime} \mathrm{N}$ and $109^{\circ} 11^{\prime} 38^{\prime \prime}$ E) are situated on the coast of the southeastern region whereas Da Nang (DN) (16 $6^{\circ} 2^{\prime} 38^{\prime \prime} \mathrm{N}$ and $108^{\circ} 11^{\prime}$ $\left.58^{\prime \prime} \mathrm{E}\right)$ and Hue (HU) $\left(16^{\circ} 28^{\prime} 0^{\prime \prime} \mathrm{N}\right.$ and $\left.107^{\circ} 36^{\prime} 0^{\prime \prime} \mathrm{E}\right)$ 
are also located on the coast of the South China Sea (Fig. 1).

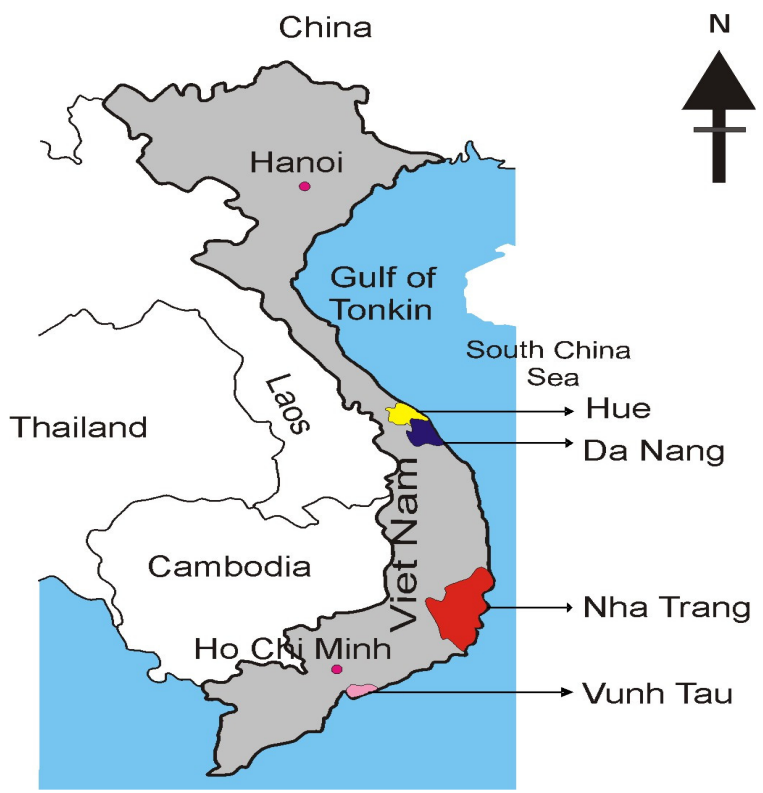

Fig. 1 Figure representing four sampling stations in the map of Viet Nam.

Vunh Tau is a most industrialized province of Viet Nam comprising petroleum (the most important), electricity, power plant, petrochemicals (urea plant, polyethylene, steel and cement industries), fishery and shrimp as well as tourism as important industries. Coastal aquaculture, tourism and a number of light industries are recognised as the major industries in the remaining three coastal zones. Mountains are the specific geographical criteria of these four zones of Viet Nam.

Mud samples (0 - 5mm) were collected from randomly selected two ponds of each four provinces during the period from September 17 to 30, 2008. Mud of two different ponds of each sampling zone were mixed properly, pooled into one and preserved in clean plastic bottle $(250 \mathrm{ml})$.

Processing and SEM-EDS analysis of mud: In the laboratory, the samples were evenly mixed and allowed for air dried. Air dried mud samples were ground with ceramic mortar and pestle to a homogeneous powder and sieved through a $0.42 \mathrm{~mm}$ mesh to get an equal size of particles for analysis. Metallic SEM specimen disks of brass were prepared with double-sided adhesive carbon mounting tapes. Dried mud powder was sprinkled onto the adhesive carbon tapes supported on metallic mounting disks and the disks were platinum coated using a JEOL JFC-1600 auto fine coater. An extensive morphological and chemical characterization of all dried muds were carried out by scanning electron microscopy (SEM) in 25x and 5000x magnification using a jeol model equipment coupled with energy dispersive spectroscopy (EDS) facility (JSM-6500F, JEOL) in the Center for Advanced Marine Core Research, Kochi University, Japan.

The software was calibrated to $\mathrm{Al}$ and $\mathrm{Cu}$ reference standard embedded in the specimen holder. The accelerating voltage for X-ray intensity measurement and for SEM image observation was $15 \mathrm{kV}$, applying 2.3A filament currents and 50A emission currents. Mean values of eighteen points of six particles $(6 \times 3)$ of powdered mud of each sampling stations were considered for data analysis.

Statistical analysis: Data was statistically interpreted using one-way ANOVA among the four stations. ANOVA was followed by a LSD (least significance difference) test using statistical package EASE and MSTAT. All statistical tests were performed at 5\% probability level.

\section{RESULTS AND DISCUSSION}

Morphological criteria: Morphological information of mud particles were obtained form SEM analysis shown in the figure 2. Mega (X25) and microscopic (X5000) pictures of the mud exhibited a wide range of shapes and surface texture for individual particle.

Elemental criteria: EDS analysis showed the clear distribution criteria of ten elements, Carbon, Phosphorous, Sulfur, Sodium, Potassium, Magnesium, Aluminium, Iron, Silicon and Titanium, whereas remaining other elements were present in very negligible percentage which was not detectable. The element specific results are as below:

Carbon (C) varied between 6.56 to $12.55 \%$ in mud of all four investigated area (Table 1). The $\mathrm{C}$ content in mud of HU was 32.6 to $91 \%$ higher than that of the remaining zones and exhibiting the following order of variations: $\mathrm{HU}>\mathrm{DN}>\mathrm{NT}>\mathrm{VT}$ (ANOVA, $\mathrm{p}>$ $0.05)$.

Likewise $\mathrm{C}$, phosphorous (P) also revealed a variation among the four zones investigated and ranging from 1.43 to $3.35 \%$. The highest and lowest values were found in mud of HU and DN, respectively (Table 1).

Sulfur (S) content in the mud of four stations ranged from 1.21 to $2.72 \%$. The maximum $\mathrm{S}$ value of $\mathrm{HU}$ $(2.72 \%)$ was 6,124 and $43 \%$ higher compared to VT, NT and DN, respectively (Table 1).

Significant variation $(0.1-3.68 \%)$ was pronounced in percentage distribution of sodium $(\mathrm{Na})$ in the four investigated regions (ANOVA, $\mathrm{p}>0.05$ ). The maximum value $(3.68 \%)$ of NT was $3.51,36.7$ and 8.06 times greater over the VT, DN and HU, respectively (Table 1). 
In four stations, the potassium $(\mathrm{K})$ content ranged from 0.69 to $3.67 \%$. The percentage content of $\mathrm{K}$ showed the following order of variations: VT $(3.67 \%)>\mathrm{HU}(2.59 \%)>\mathrm{NT}(1.07 \%)>\mathrm{DN}(0.69 \%)$ (Table 1).
Percentage of magnesium $(\mathrm{Mg})$ varied between 0.76 to $1.46 \%$ in mud of all sampling stations. No significant difference was apparent in $\mathrm{Mg}$ percentage between VT $(0.76 \%)$ and NT $(0.78 \%)$ as well as between DN (1.46\%) and HU (1.37\%) (Table 1).

Table 1. Mean values $( \pm$ S.E. $)$ of different constituting elementals in mud samples of four sampling stations.

\begin{tabular}{|c|c|c|c|c|}
\hline \multirow{2}{*}{$\begin{array}{l}\text { Constituting } \\
\text { elements } \\
\text { (\% in dry } \\
\text { wt.) }\end{array}$} & \multicolumn{4}{|c|}{ Sampling stations } \\
\hline & VT & NT & DN & $\mathrm{HU}$ \\
\hline C & $6.56 \pm 0.01^{D}$ & $7.5 \pm 0.2^{\mathrm{C}}$ & $9.46 \pm 0.005^{\mathrm{B}}$ & $12.55 \pm 1^{\mathrm{A}}$ \\
\hline $\mathrm{P}$ & $1.54 \pm 0.3^{\mathrm{C}}$ & $1.84 \pm 0.5^{\mathrm{B}}$ & $1.43 \pm 0.44^{\mathrm{C}}$ & $3.35 \pm 0.6^{\mathrm{A}}$ \\
\hline S & $2.56 \pm 0.1^{\mathrm{B}}$ & $1.21 \pm 0.03^{\mathrm{D}}$ & $1.9 \pm 0.11^{\mathrm{C}}$ & $2.72 \pm 0.5^{\mathrm{A}}$ \\
\hline $\mathrm{Na}$ & $1.04 \pm 0.02^{\mathrm{B}}$ & $3.68 \pm 0.09^{\mathrm{A}}$ & $0.1 \pm 0.022^{\mathrm{D}}$ & $0.45 \pm 0.03^{\mathrm{C}}$ \\
\hline K & $3.67 \pm 0.02^{\mathrm{A}}$ & $1.07 \pm 0.5^{\mathrm{C}}$ & $0.69 \pm 0.05^{\mathrm{D}}$ & $2.59 \pm 0.003^{\mathrm{B}}$ \\
\hline $\mathrm{Mg}$ & $0.76 \pm 0.05^{\mathrm{B}}$ & $0.78 \pm 0.03^{\mathrm{B}}$ & $1.46 \pm 0.06^{\mathrm{A}}$ & $1.37 \pm 0.1^{\mathrm{A}}$ \\
\hline $\mathrm{Al}$ & $15.9 \pm 0.9^{\mathrm{A}}$ & $13.15 \pm 1^{\mathrm{B}}$ & $4.5 \pm 0.04^{\mathrm{C}}$ & $12.80 \pm 0.5^{\mathrm{B}}$ \\
\hline $\mathrm{Fe}$ & $8.29 \pm 0.26^{\mathrm{A}}$ & $4.55 \pm 0.45^{\mathrm{B}}$ & $0.59 \pm 0.001^{\mathrm{C}}$ & $7.64 \pm 0.06^{\mathrm{A}}$ \\
\hline $\mathrm{Si}$ & $30.84 \pm 0.4^{\mathrm{B}}$ & $27.61 \pm 1.2^{\mathrm{C}}$ & $47.42 \pm 3^{\mathrm{A}}$ & $23.39 \pm 0.9^{\mathrm{D}}$ \\
\hline $\mathrm{Ti}$ & $0.65 \pm 0.1^{\mathrm{A}}$ & $0.36 \pm 0.05^{\mathrm{B}}$ & 0 & $0.54 \pm 0.005^{\mathrm{A}}$ \\
\hline
\end{tabular}

Same script among stations (rows) revealed lack of significant difference.

There was a significant variation $(4.5-15.9 \%)$ in the aluminium (Al) percentage of four stations (ANOVA, $\mathrm{p}>0.05)$. The highest percentage of $\mathrm{Al}$ in VT exhibited 20 to $253 \%$ elevated value over the remaining three stations (Table 1 ).

Likewise other elements, iron $(\mathrm{Fe})$ also showed a remarkable variation in the percentage distribution of all the stations investigated (ANOVA, $\mathrm{p}>0.05$ ). The percentage of $\mathrm{Fe}(0.59-8.29 \%)$ showed the order of variations as follows: $\mathrm{VT}>\mathrm{HU}>\mathrm{NT}>\mathrm{DN}$ (Table $1)$.

There was a noticeable significant difference (ANOVA, $\mathrm{p}>$ 0.05 ) in the percentage of silicon $(\mathrm{Si})$ ranging from 23.39 to $47.42 \%$ in the four examined muds. Maximum percentage was $47.42 \%$ in DN showing 53,71 and $102 \%$ higher values compared to that of the VT, NT and HU, respectively (Table 1)

Titanium (Ti) also showed a significant variations (0 $0.65 \%$ ) among the four investigated stations as that of other elements. Though highest value $0.65 \%$ was found in VT but no Ti was observed in the DN (Table 1).

Above results of the present study clearly demonstrated that morphological criteria and percentage distribution pattern of ten elements in muds of investigated shrimp ponds were varied significantly among the four stations. The distribution pattern also obviously revealed that all muds were predominately constituted with $\mathrm{Si}(23.39$ to $47.42 \%)$, Al $(4.5-15.9 \%)$, Fe $(0.59-8.29 \%)$ and $\mathrm{C}(6.56$ to $12.55 \%$ ). Despite that it may also be suggested from the EDS analysis, Si and Al are the first and second priority constituents followed by $\mathrm{C}$ and $\mathrm{Fe}$ of the mud in investigated shrimp ponds of four stations. $\mathrm{K}(3.67 \%), \mathrm{Al}$ $(15.9 \%), \mathrm{Fe}(8.29 \%)$ and $\mathrm{Ti}(0.65 \%)$ were distributed at highest percentage in the VT than that of the remaining three stations; $\mathrm{Na}(3.68 \%)$ was prevalent in NT; whereas
$\mathrm{Mg}(1.46 \%)$ and $\mathrm{Si}(47.42)$ were abundant in DN as well as $\mathrm{C}(12.55 \%), \mathrm{P}(3.34 \%)$ and S $(2.72 \%)$ were found with maximum percentage in HU. Results also clearly signified that highest abundance of $\mathrm{Al}, \mathrm{Fe}$ and $\mathrm{Ti}$ in VT compared to that of other three investigated areas is possibly due to high industrialization - anthropogenic sources.

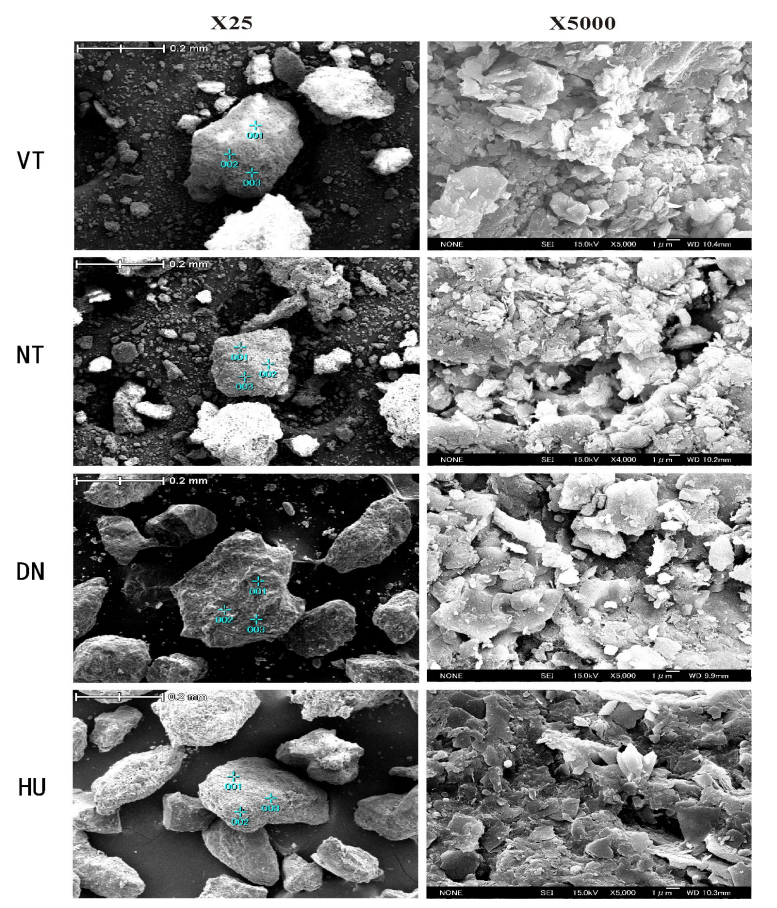

Fig. 2 SEM macro and micrographs of mud (figure represents only one particle of each sampling station) of four

A positive correlations was pronounced between the major metal constituting two elements $\mathrm{Al}$ and $\mathrm{Fe}(\mathrm{r}=0.9221)$, whereas a negative correlation was found $\mathrm{Al}$ and $\mathrm{Si}(\mathrm{r}=-$ $0.8466)$ as well as $\mathrm{Fe}$ and $\mathrm{Si}(\mathrm{r}=-0.8363)$ which clearly implied that both $\mathrm{Al}$ and $\mathrm{Fe}$ have the common industrial sources in the four investigated regions. Correlation of $\mathrm{C}$ 
with $\mathrm{Al}(\mathrm{r}=-0.3119)$ and $\mathrm{Fe}(\mathrm{r}=0.0140)$ showed a negative and very poor correlation, respectively which also signified that availability of $\mathrm{C}$ in the mud of four sampling stations is not dependent on the abundance of $\mathrm{Al}$ and $\mathrm{Fe}$.

Conclusion: Above elastration elucidates to draw the inference that mud of all shrimp ponds are principally composed with $\mathrm{Si}, \mathrm{Al}, \mathrm{Fe}$ and $\mathrm{C}$ as major elemental constituents, whereas remaining other elements are present in low percentage in the mud of shrimp pond geochemical profile of Viet Nam. Percentage composition of Fe $(0.59-$ $8.29 \%)$ and $P(1.43$ to $3.35 \%)$ are higher than that of the natural background (Approximately $\mathrm{Fe} 3.52 \%$ and $\mathrm{P}$ $0.22 \%$ ) level generally considered for soil. Excepting $\mathrm{Fe}$ and $\mathrm{P}$, all elements in the mud of the investigated ponds are appeared within the normal percentage of the geochemical elemental constitutional level of the soil. Though it is not possible to ascertain the source of all elements from this study but obtained results suggested that abundance of the $\mathrm{Al}$ and $\mathrm{Fe}$ in the mud of shrimp ponds are largely influenced by the anthropogenic sources. Further study concerning elemental constituents of mud and mountainous rock is needed to find out the origin of the abounding elements in the bottom mud. Moreover, from this study it should be mentioned that monitoring of elemental composition and their source using SEM-EDS would be a potential tool for understanding the concentration level towards conserving the coastal environment. Haley et al. (2006) proposed that SEM-EDS can provide accurate and precise concentration of elements ( $\mathrm{Al}, \mathrm{Fe}, \mathrm{Mg}, \mathrm{Ca}, \mathrm{K}$ and $\mathrm{Si}$ ) in estuarine particles as that of ICP-AES.

Acknowledgements: Authors are grateful to Govt. of Japan for sponsoring the JSPS research grant (No. 20380181) to carry out the present study. Dr. Bhakta is also grateful to Kochi University for providing the position of Researcher Faculty. We express our sincere thanks to Dr. Yuhji Yamamoto for extending his kind support in SEM-EDS analysis in the Center for Advanced Marine Core Research, Kochi University.

\section{REFERENCES}

Bhakta, JN; Biswas, JK; Jana, BB (2007). Influence of physical raking and biological process in the mudwater exchange dynamics of $\mathrm{P}$ in fish culture ponds. $\mathrm{J}$ Appl Sc Environ Manage 11(2): 71-75.

Boer, DH; Crosby, G (1995). Evaluating the potential of SEM/EDS analysis for fingerprinting suspended sediment deriving from two contrasting topsoils. Catena 24: 243-258.

Chen, Y; Schnitzer, M (1976). Scanning electron microscopy of a humic acid and of a fulvic acid and its metal and clay complexes. Soil Sci Soc Am J 40: 682686.

Chen, Y; Schnitzer, M (1976). Scanning electron microscopy of a humic acid and of a fulvic acid and its metal and clay complexes. Soil Sci Soc Am J 40: 682686.
Fergusson, JE (1990). The heavy elements: Chemistry, environmental impacts and health effects. Oxford, Pergamon Press

Harris, WG; Hollien, KA (2000). Changes across artificial E-Bh boundaries formed under simulated fluctuating water tables. Soil Sci Soc Am J 64: 967-973.

Jeong, GY (1998). Vermicular kaolinite epitactic on primary phyllosilicates in the weathering profiles of anorthosite. Clay Clay Miner 46: 509-520.

Laird, D (2001). Nature of clay-humic complexes in an agricultural soil: II. Scanning electron microscopy analysis. Soil Sci Soc Am J 65: 1419-1425.

Mitchell, RL (1974). Trace element problems in Scottish soils. Netherlands Journal of Agricultural Science 22: 7-33.

Reed, SJB (1996). Electron microprobe analysis and scanning electron microscopy in geology. Cambridge University Press, Cambridge, 1-4: 183-184.

Remley, PA; Bradford, JM (1989). Relationship of soil crust morphology to interrill erosion parameters. Soil Sci Soc Am J 53: 1215-1221.

Robertson, IDM; Eggleton, RA (1991). Weathering of granitic muscovite to kaolinite and halloysite and of plagioclase-derived kaolinite to halloysite. Clay Clay Miner 39: 113-126.

Stephen, MH; Alan, DT; Peter, RB; Mark, FF (2006). A comparison of SEM-EDS with ICP-AES for the quantitative elemental determination of estuarine particles. Environ Chem Lett 4: 235-238.

Sullivan, LA (1990). Micropiting of some clay materials adjacent structural pores. Geoderma 46: 371-376.

Tan, KH (1985). Scanning electron microscopy of humic matter as influenced by methods of preparation. Soil Sci Soc Am J 49: 1185-1191.

Tchobanoglous, G; Schroeder, ED (1987). Water Quality. Addison-Wesley Publishing Company, Reading, MA.

Tiller, KG (1989). Heavy metals in soil, their environmental significance. In: Steward BA (ed) Advances in soil science 9, New York, Springer.

Watanabe, T; Sawada, Y; Russel, JD; McHardy, WJ; Wilson, MJ (1992). The conversion of montmorillonite to interstratified halloysite-smectite by weathering in the Omi acid clay deposit, Japan. Clay Clay Miner 27: 159-173.

Wong, SC; Li, XD; Zhang, G; Qi, SH; Min, YS (2002). Heavy metals in agricultural soils of Pearl River Delta, South China. Environ Pollution 119: 33-44 . 